\title{
Does Radiofrequency Ablation Induce Neoplastic Changes in Benign Thyroid Nodules: A Preliminary Study
}

\author{
Su Min $\mathrm{Ha}^{1, *}$, Jun Young Shin ${ }^{2, *}$, Jung Hwan Baek ${ }^{3}$, Dong Eun Song ${ }^{2}$, Sae Rom Chung ${ }^{3}$, Young Jun Choi ${ }^{3}$, \\ Jeong Hyun Lee ${ }^{3}$ \\ ${ }^{1}$ Department of Radiology, Seoul National University Hospital, Seoul National University College of Medicine; ${ }^{2}$ Department of \\ Pathology, ${ }^{3}$ Department of Radiology and the Research Institute of Radiology, Asan Medical Center, University of Ulsan \\ College of Medicine, Seoul, Korea
}

Background: To evaluate the clinical feasibility of radiofrequency ablation (RFA) of benign thyroid nodules along with cytomorphological alteration, and any malignant transformation through biopsy.

Methods: The data were retrospectively collected between April 2008 and June 2013 and core needle biopsy (CNB) was performed on 16 benign thyroid nodules previously treated using RFA. The parameters of the patients were compared, between the time of enrollment and the last follow-up examination, using linear mixed model statistical analysis.

Results: No atypical cells or neoplastic transformation were detected in the undertreated peripheral portion of treated benign nodules on the CNB specimen. RFA altered neither the thyroid capsule nor the thyroid tissue adjacent to the treated area. On histopathological examinations, we observed $81.2 \%$ acellular hyalinization, which was the most common finding. After a mean follow-up period of over 5 years, the mean volume of thyroid nodule had decreased to $6.4 \pm 4.2 \mathrm{~mL}$, with a reduction rate of $81.3 \% \pm 5.8 \%(P<0.0001)$. Conclusion: RFA is a technically feasible treatment method for benign thyroid nodules, with no carcinogenic effect or tissue damage of the normal thyroid tissue adjacent to the RFA-treated zone.

Keywords: Thyroid nodule; Radiofrequency ablation; Ultrasonography; Pathology; Biopsy, large-core needle

\section{INTRODUCTION}

With the widespread use of ultrasound (US), clinically palpable nodules are found incidentally in up to $67 \%[1,2]$. With this increase in the detection of thyroid nodules, ethanol ablation (EA), laser ablation (LA), and radiofrequency ablation (RFA) have been investigated for the treatment of symptomatic thyroid nodules as acceptable alternatives to surgery [3]. US-guided RFA is a nonsurgical technique that has been used for the treatment of benign nodules because of cosmetic concerns, local

Received: 3 January 2019, Revised: 15 March 2019, Accepted: 3 April 2019 Corresponding author: Dong Eun Song

Department of Pathology, Asan Medical Center, University of Ulsan College of Medicine, 88 Olympic-ro 43-gil, Songpa-gu, Seoul 05505, Korea

Tel: +82-2-3010-5998, Fax: +82-2-3010-6962, E-mail: desong@amc.seoul.kr

*These authors contributed equally to this work. pain, and hyperthyroidism [4-6]. It has also been used in recurrent thyroid cancers and even papillary microcarcinoma in patients who are considered ineligible for surgery [7].

Several studies have assessed the pathological changes occurring after treating thyroid nodules using EA [8-10] and LA [11,12]. Dobrinja et al. [13] observed central hyaline sclerosis and scarring in RFA treated nodules with a preserved capsule, findings that did not jeopardize subsequent operations. Dobrinja et al. [13] questioned what would happen if a thyroid cancer was not detected before starting RFA and was left untreated.

Copyright $(\odot 2019$ Korean Endocrine Society

This is an Open Access article distributed under the terms of the Creative Commons Attribution Non-Commercial License (http://creativecommons.org/ licenses/by-nc/4.0/) which permits unrestricted non-commercial use, distribution, and reproduction in any medium, provided the original work is properly cited. 
They observed regrowth of follicular lesions/follicular neoplasm after RFA. Given the nodule growth is a sign of potential malignancy [14] and that the rate of malignancy is estimated to be between $14 \%$ and $48 \%$, they confirmed cancer by subsequent surgery. On the other hand, Lim et al. [15] observed a rate of only 5.6\% recurrence after RFA as a result of regrowth in the undertreated peripheral portion of benign thyroid nodules. Fineneedle aspiration (FNA) revealed that the recurrences were not associated with malignancy.

The post RFA regrowth of the undertreated peripheral portion of benign thyroid nodules should be evaluated for neoplastic transformation or the progression of undetected thyroid cancer, to ensure that this treatment method can be safely applied in cases of recurrence. It is crucial to obtain tissue for pathological analysis through a procedure less invasive than surgery. One such method can be core needle biopsy (CNB), which has been reported as a valuable diagnostic tool to be used in lieu of diagnostic surgery [16-20]. During 5-year follow-up of patients treated with RFA for benign thyroid nodules, we used CNB for whom the regrowth of the undertreated peripheral portion was noted and to determine whether this is associated with risk of malignancy. We investigated the clinical feasibility of RFA treatment along with cytomorphological alteration.

\section{METHODS}

This retrospective study was approved by the Institutional Review Board of Asan Medical Center (2017-0917). Written informed consent was obtained from all patients before the procedure. CNB was performed on 16 patients who were RFA-treated for benign thyroid nodules, in the period between April 2008

Table 1. Demographic Characteristics of the Enrolled Patients (16 Benign Nodules)

\begin{tabular}{lc}
\hline Characteristic & Radiofrequency ablation $(n=16)$ \\
\hline Gender, male:female & $1: 15$ \\
Age, yr & $43.8 \pm 12.3(18-63)$ \\
Nodule diameter, cm & $5.0 \pm 1.8(2.9-9.5)$ \\
Nodule volume, $\mathrm{mL}$ & $34.6 \pm 28.5(4.5-109.1)$ \\
Volume $<20 \mathrm{~mL}$ & 8 \\
Volume $>20 \mathrm{~mL}$ & 8 \\
Symptom score & $2.7 \pm 1.4(0-5)$ \\
Cosmetic score & $3.9 \pm 0.3(3-4)$ \\
Vascularity & $2.3 \pm 0.8(1-3)$ \\
\hline
\end{tabular}

Values are expressed as mean $\pm \mathrm{SD}$ (range). and June 2013 (Table 1). Fifteen of these patients were female and one was male, with mean age of $43.8 \pm 12.3$ years (range, 18 to 63). Cytologic or histologic results of benign thyroid nodules on FNA and CNB before RFA were categorized according to the six categories of the Bethesda System for Reporting Thyroid Cytopathology and the six categories of the Bethesda System, respectively [21,22]. All patients had refused surgery or radioiodine therapy and were referred for RFA to the Radiological Interventional Department of our thyroid center. Four patients with benign nodules had previously been treated with RFA in other hospitals and were referred to our clinic because the thyroid nodules were re-growing.

\section{Pre-ablation assessment}

Physical examination and laboratory tests were performed for all patients, followed by US scanning with a $10 \mathrm{MHz}$ probe on a real-time US system (Aplio SSA-770A, Toshiba, Otawara, Japan). Three orthogonal dimensions of the nodules (the largest diameter and two other perpendicular ones) were measured before RFA. The volume of the nodule was calculated using the following equation: $\mathrm{V}=\pi \mathrm{abc} / 6$, where $\mathrm{V}=$ volume; $\mathrm{a}=$ the largest dimension; and $\mathrm{b}$ and $\mathrm{c}=$ the other two perpendicular dimensions. The percentage of volume reduction was calculated as [(initial volume-final volume $) \times 100] /$ initial volume [23]. The composition of the nodules was classified as either solid (solid component $>50 \%$ ) or predominantly cystic (solid component between $10 \%$ and 50\%). Nodule vascularity was classified according to a four-point scale: $0=$ no signal; $1=$ peripheral signal without any central vascular signal; $2=$ peripheral and central signals in $<50 \%$; and $3=$ peripheral and central signals in $>50 \%$. Upon enrollment, patients were asked to rate their pressure symptoms on a $10 \mathrm{~cm}$ visual analog scale $(0$ to $10 \mathrm{~cm})$, with the physician also recording a cosmetic grade $(1=$ no palpable mass; 2 =invisible but palpable mass; 3 =mass visible only to an experienced clinician; and 4=easily visible mass) [24].

\section{RFA procedure}

A generator (Cool-tip, Radionics, Burlington, MA, USA) and $17-$ or 18-gauge $1,1.5$, or $2 \mathrm{~cm}$ active-tip internally cooled electrodes (Well-point RF, Taewoong Medical, Goyang, Korea) were used. Local anesthesia and a trans-isthmic approach method were utilized [24]. Nodules were treated with a moving-shot technique, beginning with 10 to $30 \mathrm{~W}$ of power. If a transient hyperechoic zone did not form at the electrode tip within 5 to 10 seconds, the power was increased by $10 \mathrm{~W}$ increments. The power was reduced or turned off if the patient could not tolerate the pain dur- 
ing ablation. Ablation was terminated when all imaginary units of the nodule had changed to transient hyperechoic zones [23]. The patients then received neck compression for 10 to 20 minutes and remained under observation for 1 to 2 hours before discharge $[23,25]$.

\section{Follow-up}

A follow-up US examination was performed 1 month after the procedure, and then annually for 5 years. Changes in size, volume, and vascularity were evaluated in each session. Therapeutic success was defined as a volume reduction greater than $50 \%$. We also described "complete ablation" as complete treatment with no discernible lesion with same echogenicity as the index nodule and no vascularity on color Doppler US. Evaluation of symptoms and cosmetic grading was also performed [23,24,26]. Additional treatment was performed if the nodules did not fulfill the criteria for complete ablation, and/or if patients complained of unresolved clinical problems $[23,25,27]$. During the followup period, $\mathrm{CNB}$ was performed using a 1.1 or $1.6 \mathrm{~cm}$ excursion 18-gauge double-action spring-activated needle (TSK Ace-cut, Create Medic, Yokohama, Japan), to evaluate ablation status of the nodule and to exclude neoplastic transformation of regrowth of the undertreated peripheral portion [28]. There was no complication related to the $\mathrm{CNB}$ procedure.

\section{Statistical analysis}

Statistical analyses were performed using IBM SPSS Statistics for Windows version 23.0 (IBM Corp., Armonk, NY, USA). Parameters were compared between each patient's initial visit and the last follow-up examination using a linear mixed model statistical analysis. The level for statistical significance was defined as $P<0.05$.

\section{Pathology}

The CNB samples of treated benign thyroid nodules were subjected to routine paraffin embedding, followed by hematoxylin and eosin (H\&E) staining. For this research, the slides were reviewed by two pathologists, who assessed various cytomorphological alterations. The location of each alteration was judged on the basis of normal thyroid tissue (Fig. 1A). "Peripheral" location was defined as any alteration within half distance from the normal thyroid tissue (Fig. 1B) and "central" was defined as more than half distance from the normal thyroid tissue (Fig. $1 \mathrm{C})$. If changes were seen in both "central" and "peripheral," the lesion was categorized as "diffuse." Cytomorphological alteration without any identifiable follicular thyroid tissue, the presence of only a normal thyroid gland, and samples containing only a few follicular cells that were considered insufficient for reaching a diagnosis, were classified as "not applicable."

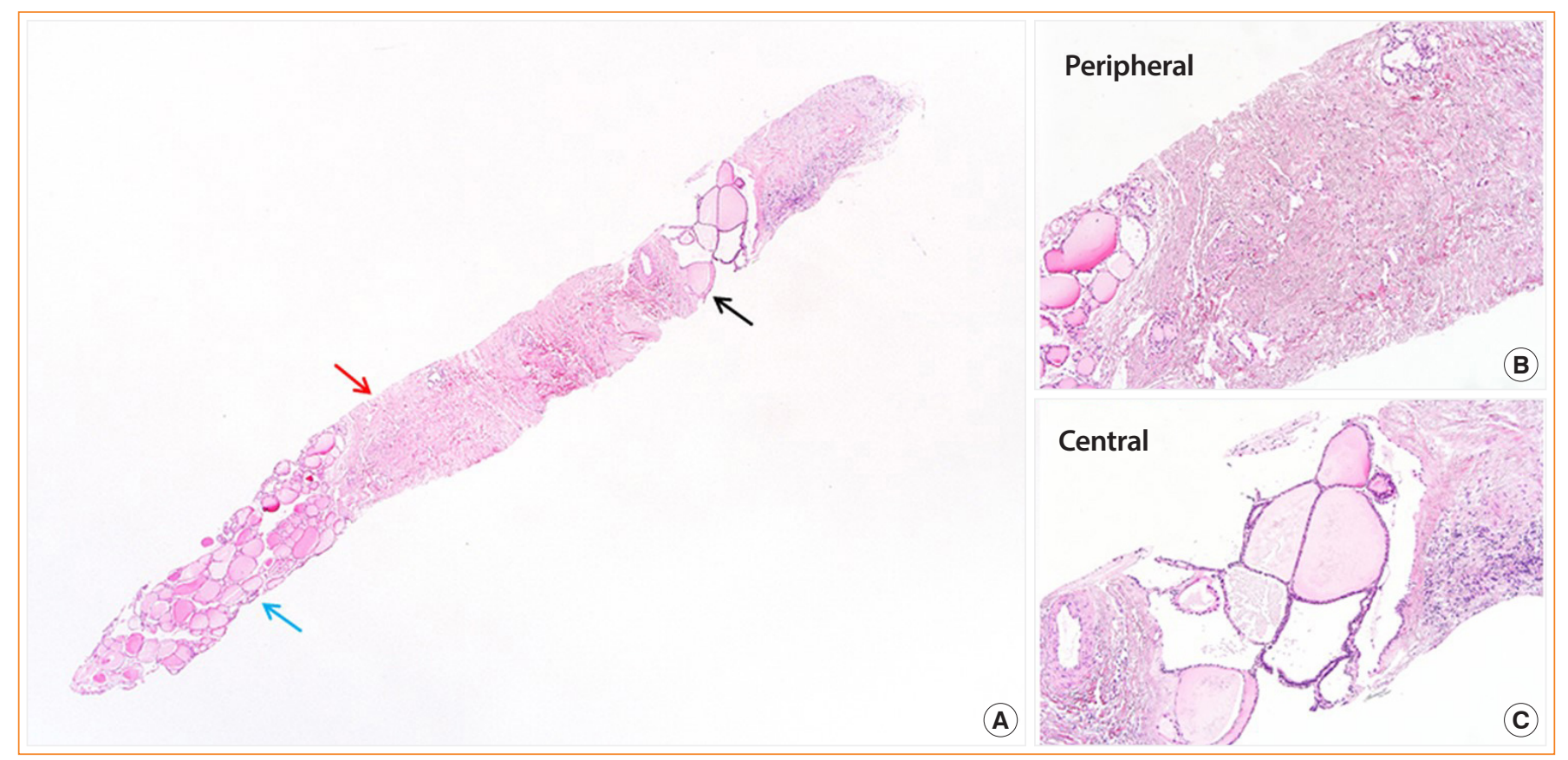

Fig. 1. Orientation of the thyroid core needle biopsy. (A) Normal thyroid tissue is noted on the left lower corner (blue arrow). (B) Less than half near the normal thyroid tissue is defined as 'peripheral' (red arrow, A). (C) More than half distance from the normal thyroid tissue is defined as 'central' (black arrow, A) with focal remaining benign follicular lesion on the central side (H\&E stain, $\times 100)$. 
Immunohistochemical staining was performed for galectin-3 (Gal-3, dilution 1:200, BenchMark XT auto-immunostainer, Novo, Ventana, AZ, USA) and Hector Battifora mesothelial cell-1 (HBME-1, dilution 1:200, BenchMark XT auto-immunostainer, Dako, Carpinteria, CA, USA), as both are considered good markers of malignancy [29,30]. Galactin-3 staining was limited to the cytoplasm and nucleus, whereas HBME-1 staining was seen along the cell membrane. To determine viability after RFA, immunohistochemical stainings for human mitochondria, thyroglobulin, thyroid transcription factor-1 (TTF-1), and paired-box gene 8 (PAX-8) were performed on one postRFA CNB specimen showing slightly viable portion on the H\&E slide (Supplemental Table S1).

\section{RESULTS}

\section{Five-year follow-up results after RFA}

Serum thyroid hormone and thyrotropin levels were within normal range in all patients before RFA, and they were treated for a single benign nodule (nodular hyperplasia, $n=7$; and nonfunctioning benign nodule, $n=8$ ). One patient had undergone EA prior to RFA procedure because of a cystic nodule that had increased in size after aspiration resulting in a cosmetic problem. The mean number of RFA sessions was $1.6 \pm 0.9$ (range, 1 to 4 ) and mean total energy deposition was $3,234.9 \pm 4,915.9 \mathrm{~J} / \mathrm{mL}$ (range, 384.9 to $19,058.0$ ) (Table 2). The mean nodule volume was $34.3 \pm 4.3 \mathrm{~mL}$ prior to treatment, which had decreased to

Table 2. Treatment Characteristics $(n=16)$

\begin{tabular}{|c|c|c|c|c|}
\hline Characteristic & Initial RFA & Additional 2nd RFA & Additional 3rd RFA & Additional 4th RFA \\
\hline RF power, $\mathrm{W}$ & $\begin{array}{c}76.3 \pm 22.9 \\
(50-120)\end{array}$ & $\begin{array}{l}48 \pm 23 \\
(10-70)\end{array}$ & $\begin{array}{l}75 \pm 21.2 \\
(60-90)\end{array}$ & 30 \\
\hline Ablation time, sec & $\begin{array}{c}672.1 \pm 661.3 \\
(150.0-2,400.0)\end{array}$ & $\begin{array}{l}355.8 \pm 177.2 \\
(120.0-550.0)\end{array}$ & $\begin{array}{l}591.0 \pm 224.9 \\
(432.0-750.0)\end{array}$ & 492.0 \\
\hline Total energy, J & $\begin{array}{c}57,110.0 \pm 69,087.7 \\
(15,000.0-216,000.0)\end{array}$ & $\begin{array}{c}16,662.0 \pm 12,362.0 \\
(850.0-27,500.0)\end{array}$ & $\begin{array}{r}46,710.0 \pm 29,401.5 \\
(25,920.0-67,500)\end{array}$ & $14,760.0$ \\
\hline Energy/mL, J & $\begin{array}{c}1,639.1 \pm 1,332.9 \\
(384.9-4,936.0)\end{array}$ & $\begin{array}{c}4,970.5 \pm 7,903.3 \\
(635.7-19,058.0)\end{array}$ & $\begin{array}{l}2,858.3 \pm 2,300.5 \\
(1,231.6-4,485.0)\end{array}$ & $1,785.0$ \\
\hline No. of RF sessions & 13 (4 outside) & 7 & 2 & 1 \\
\hline \multicolumn{5}{|l|}{ Solid component ${ }^{\mathrm{a}}$} \\
\hline Solid & 13 & - & & - \\
\hline
\end{tabular}

Values are expressed as mean $\pm \mathrm{SD}$ (range).

RFA, radiofrequency ablation; $R F$, radiofrequency.

${ }^{a}$ The solid component is defined as solid (if the solid component is $>50 \%$ ) and predominantly cystic (if the solid component is between $10 \%$ and $50 \%$ ).

Table 3. Outcomes for the Benign Thyroid Nodules $(n=16)$ after Radiofrequency Ablation

\begin{tabular}{|c|c|c|c|c|c|c|c|c|c|}
\hline Variable & Before & $1-\mathrm{mo}$ & $1-\mathrm{yr}$ & $2-\mathrm{yr}$ & $3-\mathrm{yr}$ & 4-yr & $5-\mathrm{yr}$ & Last & $P$ value $^{\mathrm{a}}$ \\
\hline Largest diameter & $5.0 \pm 0.4$ & $4.2 \pm 0.4$ & $3.4 \pm 0.4$ & $3.2 \pm 0.4$ & $3.2 \pm 0.4$ & $3.0 \pm 0.4$ & $2.8 \pm 0.4$ & $2.6 \pm 0.4$ & $<0.001$ \\
\hline Volume & $34.3 \pm 4.3$ & $16.6 \pm 4.3$ & $13.7 \pm 4.3$ & $8.6 \pm 4.2$ & $9.1 \pm 4.3$ & $8.5 \pm 4.5$ & $9.0 \pm 4.7$ & $6.4 \pm 4.2$ & $<0.001$ \\
\hline Volume reduction rate, $\%$ & & $43.2 \pm 5.8$ & $63.3 \pm 5.9$ & $71.5 \pm 5.8$ & $71.6 \pm 6.1$ & $72.9 \pm 6.7$ & $71.8 \pm 6.9$ & $81.3 \pm 5.8$ & 0.001 \\
\hline Symptom score & $2.4 \pm 0.3$ & $1.5 \pm 0.3$ & $1.2 \pm 0.3$ & $0.8 \pm 0.3$ & $0.4 \pm 0.3$ & $0.5 \pm 0.3$ & $0.9 \pm 0.4$ & $0.6 \pm 0.3$ & 0.002 \\
\hline Cosmetic score & $3.7 \pm 0.3$ & $3.0 \pm 0.3$ & $2.9 \pm 0.3$ & $2.6 \pm 0.3$ & $2.7 \pm 0.3$ & $2.6 \pm 0.3$ & $2.3 \pm 0.3$ & $2.2 \pm 0.2$ & 0.041 \\
\hline Vascularity & $2.2 \pm 0.2$ & $1.4 \pm 0.2$ & $1.5 \pm 0.2$ & $2.1 \pm 0.2$ & $1.8 \pm 0.2$ & $2.5 \pm 0.3$ & $2.5 \pm 0.3$ & $2.4 \pm 0.2$ & $<0.001$ \\
\hline Therapeutic success, $\%^{\mathrm{b}}$ & & $\begin{array}{c}7 / 13 \\
(53.9)\end{array}$ & $\begin{array}{l}10 / 12 \\
(83.3)\end{array}$ & $\begin{array}{l}11 / 13 \\
(84.6)\end{array}$ & $\begin{array}{c}9 / 11 \\
(81.8)\end{array}$ & $\begin{array}{c}6 / 8 \\
(75.0)\end{array}$ & $\begin{array}{c}6 / 7 \\
(85.7)\end{array}$ & $\begin{array}{c}13 / 13 \\
(100.0)\end{array}$ & \\
\hline
\end{tabular}

Values are expressed as least-squares mean \pm standard error or number/total number $(\%)$.

${ }^{\mathrm{a}}$ Comparison of values before and last year follow-up; ${ }^{\mathrm{b}}$ Therapeutic success (volume reduction $>50 \%$ ). 
$6.0 \pm 4.2 \mathrm{~mL}$ after a follow-up period of more than 5 years (mean, 5.8 years; range, 38 to 98 months), a volume reduction rate of $81.3 \% \pm 5.8 \%(P<0.0001)$ (Table 3$)$. None of the patients showed any signs of lymph node involvement, distant metastases, or any new suspicious findings on US imaging during the 5-year follow-up period.

\section{US findings}

The nodules were composed of mainly solid portion $(n=12)$ and predominantly solid $(n=3)$. This number does not take into account the four patients who visited our clinic in post-RFA status. After ablation, color and power Doppler US showed significant reduction of the peripheral and/or intra-nodular vascular signals due to RFA-induced necrosis $(P<0.0001)$. Additional RFA was performed if the results of the treatment did not fulfill the criteria for complete ablation. The procedure was performed after confirming that no atypical cells or neoplastic changes were present in the treated benign thyroid nodules. On the last followup, we did not observe any nodule larger than its initial size.

\section{Pathological changes}

The mean interval between RFA and CNB of benign thyroid nodules was $37.5 \pm 22.1$ months (range, 1 to 80 ). On histopathological examinations, we observed acellular hyalinization in $81.2 \%(13 / 16)$, followed by chronic inflammation in $56.2 \%$ (9/16). From the 13 cases showing acellular hyalinization (Fig. 2 ), diffuse hyalinization was found in eight (61.5\%), peripheral hyalinization in one $(7.7 \%)$, and central hyalinization in one
(7.7\%). Chronic inflammation was found diffusely in $55.5 \%$ $(5 / 9)$, centrally in $22.2 \%(2 / 9)$, and peripherally in $11.1 \%(1 / 9)$. The rest of the findings in order of prevalence were histiocytic deposition, infarction, hemorrhage, fibroblast proliferation, blackish particle, calcification, foreign body reaction, cholesterol granuloma, and cavity formation (Table 4). The procedure had neither altered the thyroid capsule nor changed the thyroid tissue adjacent to the treated area, with maintained follicular architecture and benign cytological characteristics. On immunohistochemical staining, nine out of 11 cases $(81.8 \%)$ were negative for Gal-3. The remaining two cases $(2 / 11,18.1 \%)$ were uninformative because of the absence of follicular cells. Three out of four cases $(75 \%)$ were negative for HMBE-1 and the remaining case $(1 / 4,25 \%)$ was focally positive for HMBE-1, classifying it as benign [31]. In post-RFA samples, one sample with viable areas on H\&E stain was positive for TTF-1 and thyroglobulin stainings and negative for human mitochondria antibody. Areas of total infarct were negative for all four markers (human mitochondria antibody, thyroglobulin, TTF-1, and PAX-8) (Fig. 3).

In all RFA treated nodules in our study, undertreated peripheral portions were observed. Among them, one patient underwent CNB shortly after RFA (1 month) to assess the presence of any viable tissue, and determine the need for additional treatment. An inflammatory response with a few eosinophils was observed in the CNB sample. In six nodules with a volume reduction rate of more than $90.0 \%$, acellular hyalinization $(6 / 6$, $100.0 \%)$, and histiocytic deposition $(5 / 6,83.3 \%)$ were predominantly observed. Neither the energy nor the number of RFA ses-

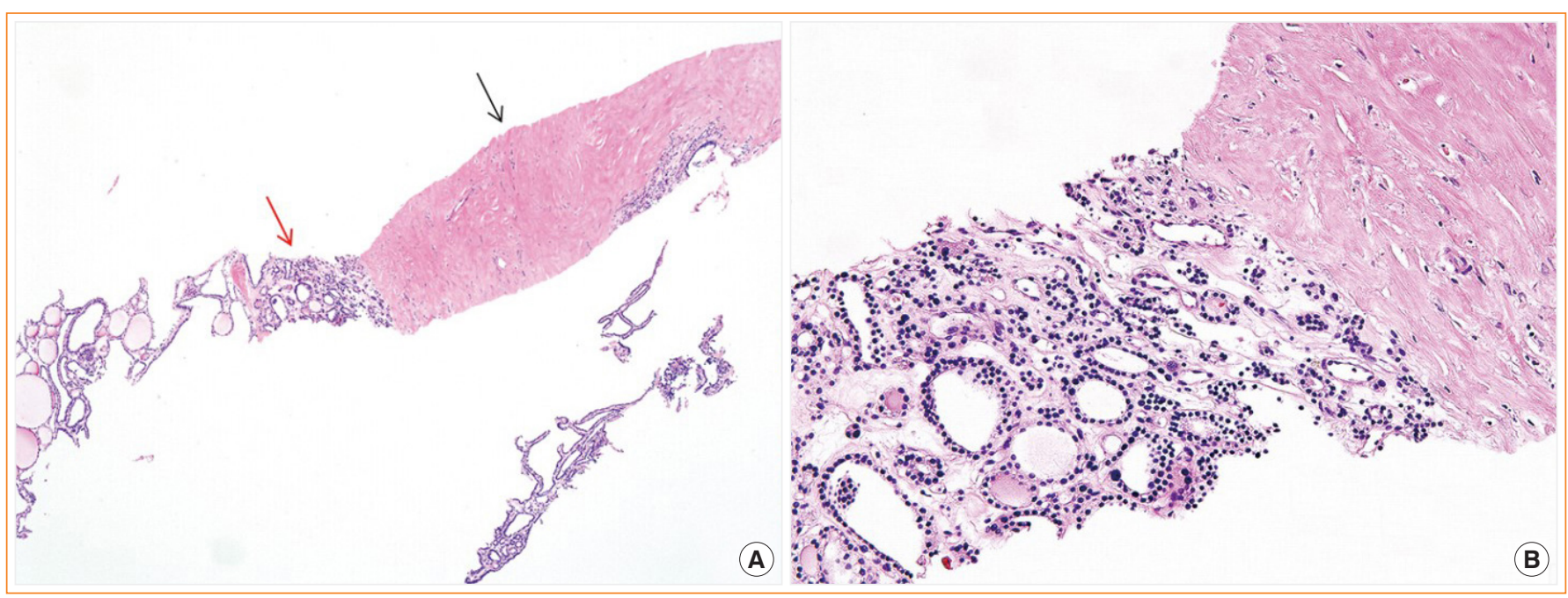

Fig. 2. Treatment effect after radiofrequency ablation (RFA) of a benign follicular nodule. (A) Note acellular dense hyalinization (black arrow) and the remaining benign follicular lesion (red arrow) $(\times 40)$. (B) The remaining benign follicular lesion shows mixed benign thyroid follicles with variable sizes and nuclear enlargement without nuclear atypia at higher magnification (H\&E stain, $\times 200)$. 


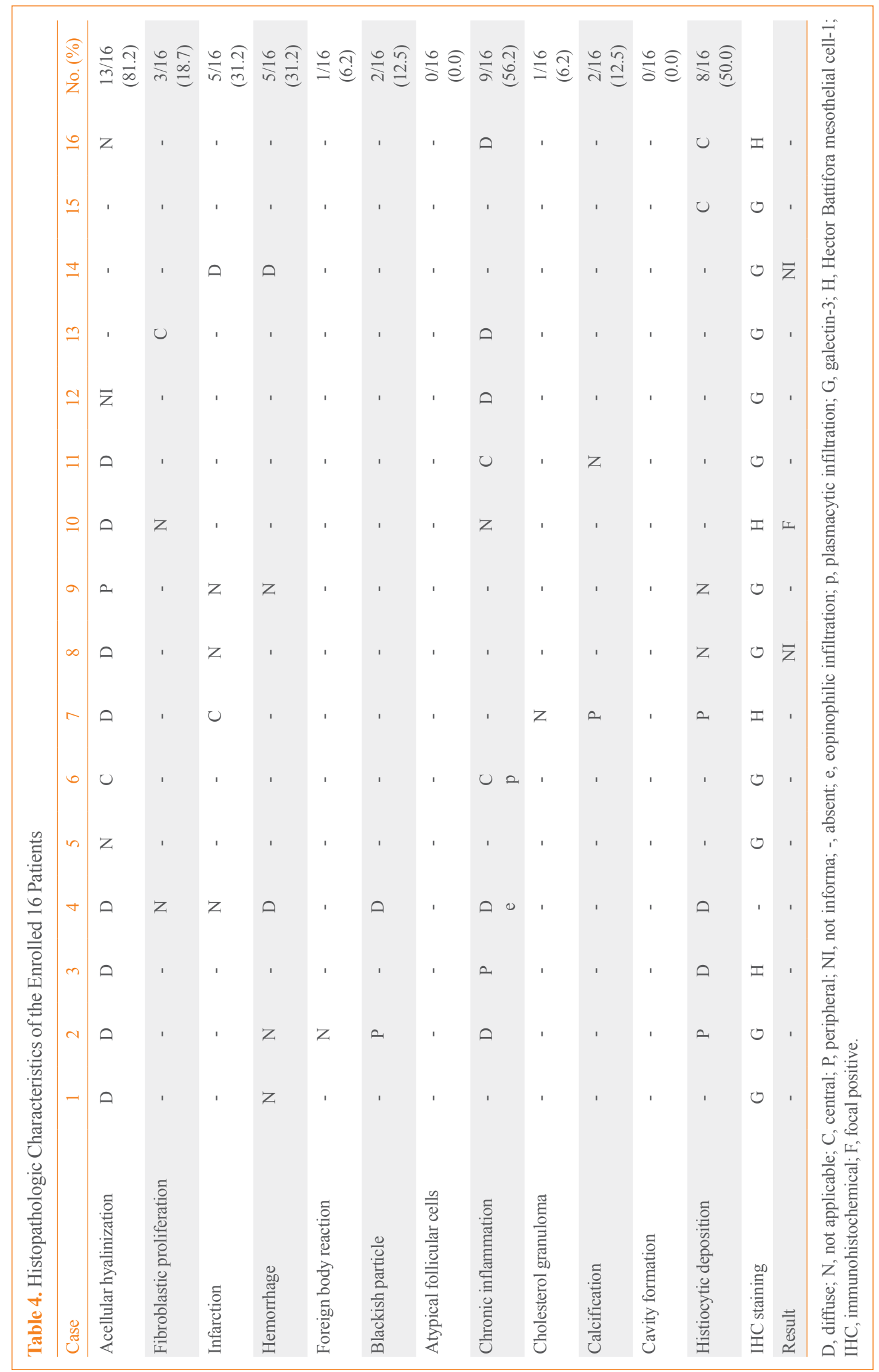




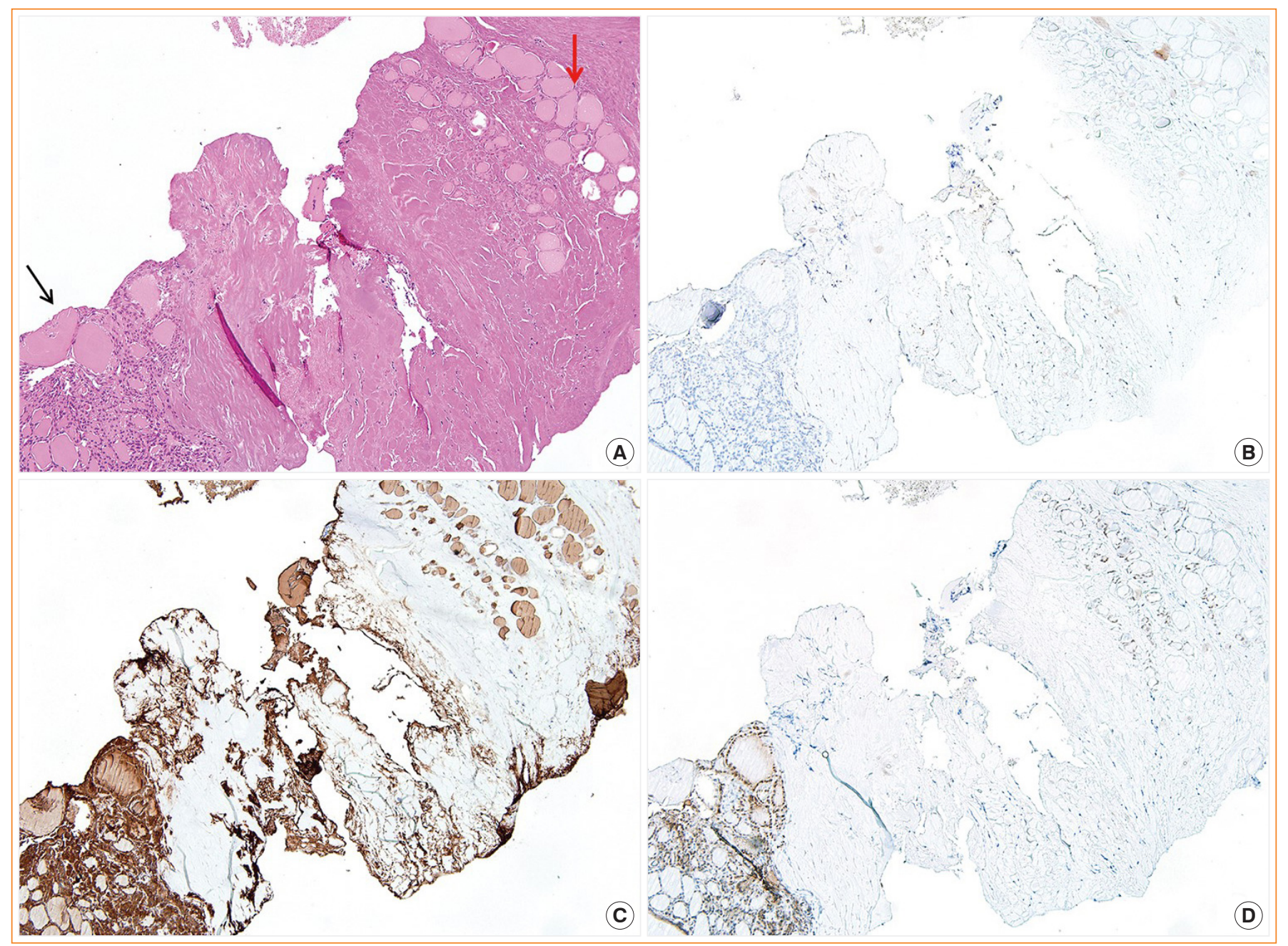

Fig. 3. Coexistence of the slightly viable area and totally infarcted area after radiofrequency ablation (RFA). (A) Slightly viable area (black arrow) and totally infarcted area after RFA (red arrow) (H\&E stain, $\times 100)$. (B) Immunohistochemical (IHC) staining for the human mitochondria antibody. Both viable and totally infarcted areas are negative for human mitochondria antibody $(\times 100)$. IHC stains for $(\mathrm{C})$ thyroglobulin and (D) thyroid transcription factor-1 (TTF-1). The totally infarcted area shows loss of expression for thyroglobulin and TTF-1, whereas the slightly viable area is positive for both $(\times 100)$.

sions significantly influenced histopathological alterations. We did not observe any clear association between the energy delivered and the amount of necrotic debris and inflammatory cells in CNB samples (Supplemental Table S2).

\section{DISCUSSION}

This is the preliminary study to evaluate whether RFA induces neoplastic transformation. No atypical cells or neoplastic changes were detected in the undertreated peripheral portion of benign thyroid nodules. We demonstrated that RFA can safely be applied to benign thyroid nodules without any atypical cells or neoplastic changes in the undertreated peripheral portion, which supports the findings in a previous study [15]. The most common pathologic finding in post-RFA biopsy specimens were acellular hyalinization $(81.2 \%)$, followed by chronic inflammation (56.2\%) and histiocytic deposition (50.0\%). RFA neither altered the thyroid capsule nor resulted in neoplastic changes in the thyroid tissue adjacent to the treated area. In 5-year followup, RFA significantly reduced the volume of benign thyroid nodules and improved cosmetic and/or symptomatic problems.

Because of the possible regrowth of the undertreated peripheral portion after RFA of benign thyroid nodules, it is crucial to determine whether RFA promotes any neoplastic transformation and whether the next management should be additional RFA treatment or surgery. Indeed, there is evidence that insufficient 
RFA facilitates undetected tumor cell progression because suboptimal heat promotes angiogenesis in non-tumor cells, such as tumor-associated endothelial cells [32,33]. Moreover, in a previous study, Dobrinja et al. [13] observed regrowth of follicular lesions/follicular neoplasm after RFA. Given that regrowth after RFA can be a sign of potential malignancy [14], RFA treated follicular neoplasm underwent surgery and revealed the regrowth to be cancer transformation. Our study supported that RFA treatment of benign thyroid nodules can be safely applied without the need for further pathological confirmation of undertreated peripheral portion.

Most benign nodules grow slowly over time [34], but there is no consensus as to what constitutes significant growth, warranting re-biopsy [34,35]. The American Thyroid Association recommends a repeated biopsy [36] if there is evidence of nodule growth. Recently, CNB has been reported to be a valuable diagnostic tool that can be used to reduce the incidence of diagnostic surgery $[16,17]$. Indeed, for patients with benign thyroid nodules surgery seems to be an excessive procedure to confirm neoplastic transformation not detected on US. The advantages of a properly obtained CNB sample of thyroid nodules are its ability to sample large amounts of tissue, assess histologic architecture rather than cytological evaluation and the fact that is not very operator dependent [28]. Previous study revealed that $\mathrm{CNB}$, including the center and periphery of the nodules, provide histologic information regarding degenerative changes [16]. In the present study, the cytolomorphological changes after RFA included both features of tissue damage, such as the presence of histiocytes and hemorrhage, and features of irreversible damage, such as infarction, cavity formation, fibroblast proliferation, and acellular hyalinization. No atypical or malignant follicular cells were identified in our study. Acellular hyalinization was the most common finding that may cause a long-lasting impact in decreasing nodule volume during the follow-up period. Our pathological findings after RFA for benign nodules may reflect a process of progressive reabsorption of necrotic material by macrophages and replacement with fibrous scar similar to that seen in LA [11]. Moreover, RFA did not alter the follicular architecture or the tumor capsule, which may be due to retaining the active tip within the nodule throughout the procedure, hence undertreating areas near the thyroid capsule. These findings could explain previous study results [13], which revealed that RFA treated thyroid lesions does not induce perithyroidal fibrosis, therefore not interfering with later surgery. By contrast, EA can cause perithyroidal fibrosis due to ethanol leakage during the treatment [37].
Sim et al. [38] suggested vital volume tracing as one of the earlier signs of regrowth compared to tracing total volume, which includes ablated volume. They observed regrowth beginning 12 months after treatment with a second peak later than 5 years, and suggested additional ablation sessions may be necessary to prevent long-term regrowth. Moreover, limitation of RFA approach is that US does not allow detecting very small tumor foci within the thyroid or in locoregional lymph nodes. However, the present study demonstrated the applicability of RFA for treating benign thyroid nodules, with a reduction in volume during the 5-year follow-up, resolution of related symptoms and cosmetic problems, and no life-threatening complication, sequelae, or unnecessary surgery. Our clinical success might have been due to our use of the moving shot technique, which is well known to ablate the peripheral portion of thyroid nodules and prevent marginal recurrence, which is a major cause of recurrent symptom [23].

There are several limitations of our study: it was a retrospective study, which could cause a selection bias; the follow-up period was short and our sample size was small which might not be reflective of a larger population. Moreover, there are no definitive guidelines on how to use CNB to evaluate RFA treated benign nodules for malignant transformation, resulting in a wide range in the time between RFA and CNB. Nevertheless, we demonstrated that RFA does not induce neoplastic transformation within regrowth of the undertreated peripheral portion on CNB specimens, and does not hinder a subsequent thyroid surgery because of the preservation of the thyroid capsule. Finally, we only examined histologic changes in CNB and not surgical specimens. Nonetheless, during monitoring of post-RFA patients with benign thyroid nodules, CNB usage in lieu of surgery to observe further histopathological changes provided possible rationale for an additional RFA in the case of regrowth.

In conclusion, this preliminary study demonstrated that RFA is effective in treating benign thyroid nodules without any carcinogenic effect based on the cytolomorphological changes of follow-up CNBs. RFA did not induce tissue damage in the normal thyroid tissue adjacent to the RFA treated zone, thus not interfering with future surgery.

\section{CONFLICTS OF INTEREST}

No potential conflict of interest relevant to this article was reported. 


\section{AUTHOR CONTRIBUTIONS}

Conceptualization: J.H.B., D.E.S. Data curation: S.M.H., J.Y.S. Formal analysis: S.M.H. Methodology: S.M.H., J.Y.S. Validation: S.R.C., Y.J.C., J.H.L. Writing (original draft): S.M.H., J.Y.S. Writing (review \& editing): S.M.H., J.Y.S., J.H.B., D.E.S.

\section{ORCID}

Su Min Ha https://orcid.org/0000-0002-1833-0919

Jun Young Shin https://orcid.org/0000-0002-4833-9738

Jung Hwan Baek https://orcid.org/0000-0003-0480-4754

Dong Eun Song https://orcid.org/0000-0002-9583-9794

Sae Rom Chung https://orcid.org/0000-0003-4219-7166

Young Jun Choi https://orcid.org/0000-0001-7098-5042

Jeong Hyun Lee https://orcid.org/0000-0002-0021-4477

\section{REFERENCES}

1. Tunbridge WM, Evered DC, Hall R, Appleton D, Brewis M, Clark F, et al. The spectrum of thyroid disease in a community: the Whickham survey. Clin Endocrinol (Oxf) 1977;7: 481-93.

2. Vander JB, Gaston EA, Dawber TR. The significance of nontoxic thyroid nodules. Final report of a 15-year study of the incidence of thyroid malignancy. Ann Intern Med 1968; 69:537-40.

3. Gharib H, Hegedus L, Pacella CM, Baek JH, Papini E. Clinical review: nonsurgical, image-guided, minimally invasive therapy for thyroid nodules. J Clin Endocrinol Metab 2013; 98:3949-57.

4. Bernardi S, Dobrinja C, Fabris B, Bazzocchi G, Sabato N, Ulcigrai $\mathrm{V}$, et al. Radiofrequency ablation compared to surgery for the treatment of benign thyroid nodules. Int J Endocrinol 2014;2014:934595.

5. Faggiano A, Ramundo V, Assanti AP, Fonderico F, Macchia PE, Misso C, et al. Thyroid nodules treated with percutaneous radiofrequency thermal ablation: a comparative study. J Clin Endocrinol Metab 2012;97:4439-45.

6. Hamidi O, Callstrom MR, Lee RA, Dean D, Castro MR, Morris JC, et al. Outcomes of radiofrequency ablation therapy for large benign thyroid nodules: a mayo clinic case series. Mayo Clin Proc 2018;93:1018-25.

7. Kim JH, Baek JH, Sung JY, Min HS, Kim KW, Hah JH, et al. Radiofrequency ablation of low-risk small papillary thyroidcarcinoma: preliminary results for patients ineligible for surgery. Int J Hyperthermia 2017;33:212-9.

8. Bennedbaek FN, Karstrup S, Hegedus L. Percutaneous ethanol injection therapy in the treatment of thyroid and parathyroid diseases. Eur J Endocrinol 1997;136:240-50.

9. Crescenzi A, Papini E, Pacella CM, Rinaldi R, Panunzi C, Petrucci L, et al. Morphological changes in a hyperfunctioning thyroid adenoma after percutaneous ethanol injection: histological, enzymatic and sub-microscopical alterations. J Endocrinol Invest 1996;19:371-6.

10. Monzani F, Caraccio N, Basolo F, Iacconi P, LiVolsi V, Miccoli P. Surgical and pathological changes after percutaneous ethanol injection therapy of thyroid nodules. Thyroid 2000; 10:1087-92.

11. Piana S, Riganti F, Froio E, Andrioli M, Pacella CM, Valcavi R. Pathological findings of thyroid nodules after percutaneous laser ablation: a series of 22 cases with cyto-histological correlation. Endocr Pathol 2012;23:94-100.

12. Valcavi R, Piana S, Bortolan GS, Lai R, Barbieri V, Negro R. Ultrasound-guided percutaneous laser ablation of papillary thyroid microcarcinoma: a feasibility study on three cases with pathological and immunohistochemical evaluation. Thyroid 2013;23:1578-82.

13. Dobrinja C, Bernardi S, Fabris B, Eramo R, Makovac P, Bazzocchi G, et al. Surgical and pathological changes after radiofrequency ablation of thyroid nodules. Int J Endocrinol 2015;2015:576576.

14. Kuma K, Matsuzuka F, Kobayashi A, Hirai K, Morita S, Miyauchi A, et al. Outcome of long standing solitary thyroid nodules. World J Surg 1992;16:583-7.

15. Lim HK, Lee JH, Ha EJ, Sung JY, Kim JK, Baek JH. Radiofrequency ablation of benign non-functioning thyroid nodules: 4-year follow-up results for 111 patients. Eur Radiol 2013;23:1044-9.

16. Austin PC, Lee DS, D’Agostino RB, Fine JP. Developing points-based risk-scoring systems in the presence of competing risks. Stat Med 2016;35:4056-72.

17. Yeon JS, Baek JH, Lim HK, Ha EJ, Kim JK, Song DE, et al. Thyroid nodules with initially nondiagnostic cytologic results: the role of core-needle biopsy. Radiology 2013;268: 274-80.

18. Na DG, Baek JH, Jung SL, Kim JH, Sung JY, Kim KS, et al. Core needle biopsy of the thyroid: 2016 consensus statement and recommendations from Korean Society of Thyroid Radiology. Korean J Radiol 2017;18:217-37.

19. Jung CK, Baek JH. Recent advances in core needle biopsy for thyroid nodules. Endocrinol Metab (Seoul) 2017;32:407-12. 
20. Trimboli P, Giovanella L. The significance of having an excellent patient's comfort with thyroid core needle biopsy. Endocrinol Metab (Seoul) 2018;33:53-4.

21. Cibas ES, Ali SZ; NCI Thyroid FNA State of the Science Conference. The Bethesda System for reporting thyroid cytopathology. Am J Clin Pathol 2009;132:658-65.

22. Jung CK, Min HS, Park HJ, Song DE, Kim JH, Park SY, et al. Pathology reporting of thyroid core needle biopsy: a proposal of the Korean Endocrine Pathology Thyroid Core Needle Biopsy Study Group. J Pathol Transl Med 2015;49: 288-99.

23. Jeong WK, Baek JH, Rhim H, Kim YS, Kwak MS, Jeong $\mathrm{HJ}$, et al. Radiofrequency ablation of benign thyroid nodules: safety and imaging follow-up in 236 patients. Eur Radiol 2008; 18:1244-50.

24. Na DG, Lee JH, Jung SL, Kim JH, Sung JY, Shin JH, et al. Radiofrequency ablation of benign thyroid nodules and recurrent thyroid cancers: consensus statement and recommendations. Korean J Radiol 2012;13:117-25.

25. Spiezia S, Garberoglio R, Milone F, Ramundo V, Caiazzo C, Assanti AP, et al. Thyroid nodules and related symptoms are stably controlled two years after radiofrequency thermal ablation. Thyroid 2009;19:219-25.

26. Lee JH, Kim YS, Lee D, Choi H, Yoo H, Baek JH. Radiofrequency ablation (RFA) of benign thyroid nodules in patients with incompletely resolved clinical problems after ethanol ablation (EA). World J Surg 2010;34:1488-93.

27. Kim YS, Rhim H, Tae K, Park DW, Kim ST. Radiofrequency ablation of benign cold thyroid nodules: initial clinical experience. Thyroid 2006;16:361-7.

28. Na DG, Kim JH, Sung JY, Baek JH, Jung KC, Lee H, et al. Core-needle biopsy is more useful than repeat fine-needle aspiration in thyroid nodules read as nondiagnostic or atypia of undetermined significance by the Bethesda system for reporting thyroid cytopathology. Thyroid 2012;22:468-75.

29. Cochand-Priollet B, Dahan H, Laloi-Michelin M, Polivka M, Saada M, Herman P, et al. Immunocytochemistry with cytokeratin 19 and anti-human mesothelial cell antibody (HBME1) increases the diagnostic accuracy of thyroid fineneedle aspirations: preliminary report of 150 liquid-based fine-needle aspirations with histological control. Thyroid 2011;21:1067-73.

30. Fadda G, Rossi ED, Raffaelli M, Pontecorvi A, Sioletic S, Morassi F, et al. Follicular thyroid neoplasms can be classified as low- and high-risk according to HBME-1 and galectin-3 expression on liquid-based fine-needle cytology. Eur J Endocrinol 2011;165:447-53.

31. Dunderovic D, Lipkovski JM, Boricic I, Soldatovic I, Bozic V, Cvejic D, et al. Defining the value of CD56, CK19, galectin 3 and HBME-1 in diagnosis of follicular cell derived lesions of thyroid with systematic review of literature. Diagn Pathol 2015;10:196.

32. Ke S, Ding XM, Kong J, Gao J, Wang SH, Cheng Y, et al. Low temperature of radiofrequency ablation at the target sites can facilitate rapid progression of residual hepatic VX2 carcinoma. J Transl Med 2010;8:73.

33. Kong J, Kong J, Pan B, Ke S, Dong S, Li X, et al. Insufficient radiofrequency ablation promotes angiogenesis of residual hepatocellular carcinoma via HIF-1 $\alpha$ /VEGFA. PLoS One 2012;7:e37266.

34. Alexander EK, Hurwitz S, Heering JP, Benson CB, Frates MC, Doubilet PM, et al. Natural history of benign solid and cystic thyroid nodules. Ann Intern Med 2003;138:315-8.

35. Frates MC, Benson CB, Charboneau JW, Cibas ES, Clark $\mathrm{OH}$, Coleman BG, et al. Management of thyroid nodules detected at US: Society of Radiologists in Ultrasound consensus conference statement. Radiology 2005;237:794-800.

36. Cooper DS, Doherty GM, Haugen BR, Kloos RT, Lee SL, Mandel SJ, et al. Management guidelines for patients with thyroid nodules and differentiated thyroid cancer. Thyroid 2006;16:109-42.

37. Park HS, Baek JH, Choi YJ, Lee JH. Innovative techniques for image-guided ablation of benign thyroid nodules: combined ethanol and radiofrequency ablation. Korean J Radiol 2017;18:461-9.

38. Sim JS, Baek JH, Lee J, Cho W, Jung SI. Radiofrequency ablation of benign thyroid nodules: depicting early sign of regrowth by calculating vital volume. Int J Hyperthermia 2017;33:905-10. 